\title{
Urbanização dispersa e mobilidade no contexto metropolitano de Natal: a dinâmica da população e a ampliação do espaço de vida'
}

\author{
Urban sprawl and mobility in the metropolitan region of Natal: population \\ dynamics and life space expansion
}

Ricardo Ö̈ma, Felipe Ferreira Monteiro, Tiago Carlos Lima do Nascimento

Universidade Federal do Rio Grande do Norte (UFRN), Natal, RN, Brasil

\section{Resumo}

Embora ainda coexistam no espaço urbano o modelo concêntrico e o disperso de urbanização, considerase aqui que esse fenômeno reflete mais a cristalização e materialidade dos processos anteriores do que a perpetuação da mesma dinâmica urbana que os fizeram existir. A hipótese perseguida é a de que há um novo padrão de urbanização disperso e fragmentado que tem tornado o tecido urbano socialmente mais heterogêneo e que tal característica coloca novos desafios tanto para a esfera social quanto para a escala individual. Assim, apresenta-se o processo de expansão urbano da Região Metropolitana de Natal (RMN), a partir de uma abordagem espacial e demográfica, em direção ao eixo sul de desenvolvimento urbano. Nesse sentido, observar as transformações ocorridas ao longo da década de 2000 nos permite compreender a dimensão do fenômeno e do processo de dispersão urbana na região e ainda analisar o seu impacto. Os resultados permitem confirmar a ampliação dos espaços de vida associados a uma tendência para a dispersão urbana no sentido sul da RMN, indicando que tais processos também estão por ocorrer em regiões metropolitanas nordestinas.

Palavras-chave: Dispersão urbana. Fragmentação. Região metropolitana. Espaço de vida.

\section{Abstract}

Although the concentric and dispersed models of urbanization still coexist in urban space, we consider that this phenomenon reflects more the crystallization and materiality of the former processes than its perpetuation in urban dynamics nowadays. The hypothesis pursued is that of a new pattern of dispersed and fragmented urbanization that has made urban frames more socially heterogeneous, and that this characteristic poses new

\footnotetext{
1 Trabalho desenvolvido no âmbito do projeto "Urbanização, condições de vida e mobilidade espacial da população no contexto dos biomas nordestinos: repensando as heterogeneidades intra-regionais" (Edital MCTI/CNPq/MEC/CAPES n. 18/2012 - Ciências Humanas, Sociais e Sociais Aplicadas, processo: 403853/2012-5). Esta é uma versão revisada e ampliada de trabalho originalmente apresentado no XV Encontro da Associação Nacional de Programas de Pós-graduação e Pesquisa em Planejamento Urbano e Regional (ENANPUR).
}

R0 é Sociólogo, doutor em Demografia, e-mail: ricardo.ojima@gmail.com FFM é Arquiteto e urbanista, mestrando em Demografia, e-mail: felipefmonteiro@gmail.com TCLN é Geógrafo, mestrando em Demografia, e-mail: tiago.tcln@gmail.com 
challenges to both the social sphere and the individual scale. Thus we present the process of urban expansion in the Metropolitan Region of Natal (MRN), from a spatial and demographic approach, towards the south axis of urban development. In this sense, observing the changes occurred throughout the 2000s, allows us to understand the dimension of this phenomenon and of the urban sprawl process in the study region, and further analyze their impact. The results confirm the expansion of life space associated with a trend to urban sprawl in the south axis of the MRN, therefore indicating that such processes can also occur in other metropolitan areas of northeastern Brazil.

Keywords: Urban sprawl. Fragmentation. Metropolitan area. Life space.

\section{Introdução}

As cidades brasileiras tradicionalmente têm sido caracterizadas pela sua concentração na faixa litorânea do país, resquício do seu processo histórico de colonização e do adensamento populacional nas capitais, fruto de um intenso e acelerado processo de transição urbana que ocorreu no país em meados do século 20 (Andrade \& Andrade, 2003). Com isso, o bioma da Mata Atlântica, que representa praticamente toda a faixa litorânea, abrigava $57 \%$ da população brasileira sendo que, destes, $90 \%$ viviam em áreas classificadas como urbanas, segundo os dados do Censo Demográfico 2010 (Martine \& Ojima, 2012).

As mudanças nos modos de produção econômica e de reprodução social tornaram a cidade o lócus simultâneo de conflito e redenção dos grandes dilemas sociais contemporâneos (UNFPA, 2007). Portanto, ao tentarmos compreender a cidade e os centros urbanos, não é possível analisar apenas os volumes absolutos do crescimento populacional, pois devem se considerar também as diferentes formas de produção do espaço urbano através de suas intencionalidades e do simbolismo que reproduzem as desigualdades socioespaciais para compreendermos as formas de organização social através da relação população e espaço (Gomes, 2012).

Assim, o componente populacional nos estudos urbanos tende a ser analisado a partir de uma leitura crítica da concentração populacional urbana, em detrimento de uma análise que relacione tanto os processos de ocupação e reordenamento espacial quanto os fluxos demográficos associados a eles. Dessa forma, os problemas urbanos costumam ser tratados como resultados perversos da concentração da população. Ou seja, há um consenso implícito de que a elevada densidade demográfica associada às migrações deveria ser evitada e, portanto, deveria ser alvo de políticas públicas no sentido de reduzir os dilemas urbanos contemporâneos e ignorando a complexidade das tendências demográficas atuais.

Mas esse intenso processo de urbanização nas cidades foi simultâneo ao processo de transição demográfica no Brasil, com uma redução muito rápida das taxas de mortalidade, acompanhado posteriormente de uma redução nas taxas de natalidade. Isso causou um período transitório de intenso crescimento populacional na história do país, mas que hoje já se encontra em patamares de estabilização, mas que, acompanhado pelo processo de transição urbana, redundou em um contexto único na história da urbanização, tendo a mobilidade populacional um importante papel para compreendermos a formação deste processo (Ojima \& Marandola, 2012). Como podemos observar na Figura 1, a taxa de crescimento da população urbana era muito mais expressiva do que o crescimento da população brasileira como um todo, mas nos dias de hoje as duas taxas são praticamente idênticas, indicando que o ritmo de crescimento da população brasileira é praticamente todo urbano e, agora, em níveis muito mais baixos.

Mas dado o elevado ritmo do crescimento populacional do passado, a cidade brasileira foi incapaz de prover as vertentes básicas do desenvolvimento urbano: a melhoria da qualidade de vida e o aumento da justiça social (Souza, 2006). Destarte, boa parte das cidades dos países de industrialização tardia, tornaram-se incapazes de suprir a sociedade com formas de produção mais horizontais, incentivando a superexploração da força de trabalho, aumentando assim a segregação socioespacial da população citadina, impedindo o 


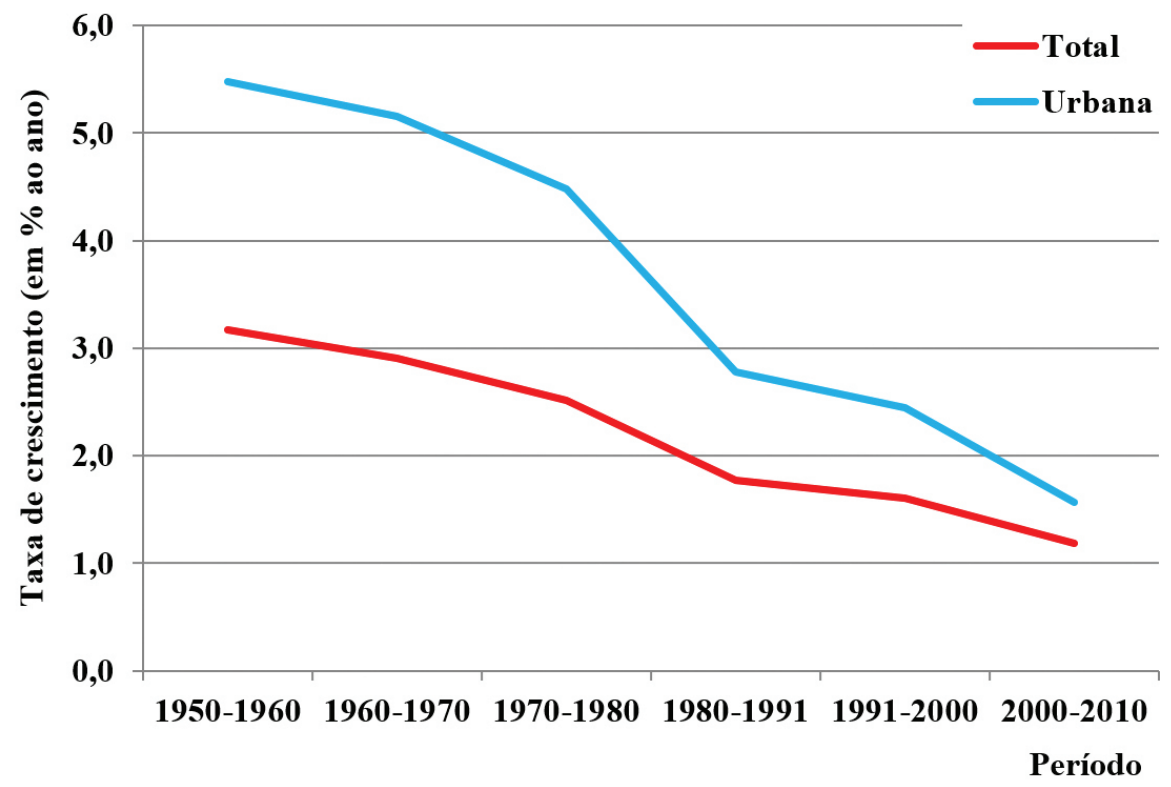

Figura 1 - Taxa de crescimento populacional total e urbano, Brasil (1950 a 2010)

Fonte: Dados dos censos demográficos do IBGE $(1950,1960,1970,1980,1991,2000,2010)$ trabalhados pelo autor.

acesso aos bens de consumo produzidos na cidade e dificultando o acesso à própria cidade e ao uso de bens, serviços e espaços públicos (Gottdiener, 2010; Harvey, 2004).

Nesse processo de desenvolvimento urbano é importante destacar também que essa segregação socioespacial se dá de forma extremamente perversa através da especulação dos agentes imobiliários e nas dificuldades encontradas pelos mais pobres no acesso ao solo urbano. Sem muitas escolhas, a não ser ocupar áreas menos valorizadas, restaria à população mais pobre a ocupação de áreas de risco (Ojima \& Marandola, 2012). Ou seja, a ausência de um planejamento urbano preocupado com a justiça social transfere para o indivíduo a ação de pensar a sua própria mobilidade espacial e, portanto, a sua ocupação no contexto regional e metropolitano. Esses são elementos que nos auxiliam a compreender a ocupação nas áreas que se configuram com características de vulnerabilidade social e ambiental. Isso também contribui para o aumento das distâncias percorridas no cotidiano da população, para fazerem uso de bens, serviços ou se realizarem como força de trabalho, coisas que não podem ser feitas nesses espaços de vulnerabilidade.

A experiência brasileira, de modo geral, apresentou uma orientação de políticas urbanas onde as áreas de menor valorização imobiliária se localizavam em áreas distantes dos centros urbanos consolidados devido ao desprovimento de serviços e infraestrutura. Assim, configurou-se uma estruturação urbana baseada na dicotomia centroperiferia/rico-pobre. Entretanto, essa periferia pobre e estigmatizada das metrópoles, muitas vezes denominada "cidades-dormitório", já não é tão homogênea como no passado. Novos padrões e modelos de consumo do espaço periférico surgem, especialmente nos contextos metropolitanos, e complexificam a análise do processo de expansão urbano recente (Ojima et al., 2010) e, principalmente, dificultando a capacidade de gestão e de adaptação aos riscos compartilhados entre os diversos atores envolvidos (Ojima \& Marandola, 2012).

Embora esse modelo concêntrico ainda se mantenha como característica predominante no tecido urbano, considera-se que este é um fenômeno que reflete a cristalização e materialidade de processos anteriores, mas que vem passando por mudanças e ganhando distinções dos períodos anteriores. Diferentemente da abordagem conduzida por Abramo (2007), no qual é analisada a dinâmica dos mercados formais e informais do uso do solo em um movimento simultâneo e sobreposto de compactação e difusão, a hipótese que se pretende desenvolver neste artigo é de que há um padrão de urbanização disperso e fragmentado que 
contribui para um tecido urbano socialmente mais heterogêneo que extrapola os limites da cidade. $\mathrm{Ou}$ seja, a incorporação da mobilidade intermunicipal enquanto estratégia de vida da sociedade móvel (Urry, 2007) coloca um novo desafio que se sobrepõe, inclusive, às eventuais permanências de compactação que coexistam a esses novos modelos de ocupação do espaço. Enfim, espera-se contribuir para entender as características que colocam novos desafios e custos sociais tanto para a esfera social quanto para a escala individual.

Para ilustrar essa dinâmica, apresentaremos o processo de expansão urbano da Região Metropolitana de Natal (RMN) dando ênfase na direção do eixo sul de desenvolvimento urbano metropolitano e partindo de uma abordagem demográfica. As metrópoles nordestinas, como apontado por Ojima (2007), poderiam ser classificadas como aglomerações urbanas compactas, pois apresentavam - com base nos dados do Censo Demográfico 2000 (IBGE, 2000) - maiores densidades demográficas em áreas urbanas, menores índices de fragmentação de áreas urbanizadas e maior grau de polarização das sedes metropolitanas em relação aos deslocamentos pendulares ${ }^{2}$ da região. Assim, observar as transformações ocorridas ao longo da década de 2000 nos permite observar com detalhe a dimensão do processo de dispersão urbana na região. Enfim, a dispersão está diretamente relacionada ao aumento da mobilidade das pessoas nos contextos de aglomerações urbanas.

\section{Dispersão urbana: sentidos demográficos}

Historicamente, a expansão urbana brasileira se deu a partir do crescimento de uma mancha urbana contínua a se espraiar, a partir do que identificávamos como cidade, sobre um espaço periférico não urbanizado, normalmente dentro dos limites de um mesmo município. Hoje este processo parece assumir novas formas e se dá de maneira fragmentada sem que ocorra necessariamente uma continuidade física entre os núcleos urbanos e com

\footnotetext{
2 O Censo Demográfico brasileiro registra a informação de deslocamentos diário entre residência e trabalho. Esta informação é denominada como deslocamento pendular ou pendularidade e difere da informação de migração, pois não caracteriza mudança permanente de residência.
}

novos significados para o espaço urbano (Limonad, 2007; Ojima, 2007, 2008; Hogan \& Ojima, 2008; Reis, 2006; Polidoro et al., 2012).

Diferente do processo de periurbanização (Santoro \& Bonduki, 2009; Hogan \& Ojima, 2008), essa é uma dimensão que não é associada ao transbordamento puro e simples da mancha urbana da sede metropolitana fagocitando o seu entorno imediato, pois a descontinuidade desta mancha é compensada pela capacidade (ou necessidade) de deslocamento demográfico entre áreas urbanizadas, mas conectadas por fluxos regulares de idas e vindas cotidianas. Essa é uma das características essenciais do processo de dispersão urbana como entendemos aqui, e sugere que o espaço de vida urbano espacialmente desconectado da mancha urbana central é um novo valor agregado aos processos de ocupação urbana mais recente (Ojima, 2007; Hogan \& Ojima, 2008).

De acordo com tais estudos, essas espacialidades dispersas são de aglomerações urbanas que apresentam principalmente baixa densidade populacional, urbanização horizontalizada, e uma maior dependência de transporte individual. Essas características se destacam nas regiões metropolitanas, embora não seja exclusiva delas. De acordo com Ojima (2008, p. 47), “[...] duas aglomerações urbanas podem apresentar taxas de crescimento populacional semelhantes no mesmo período, mas pode configurar uma forma urbana compacta, verticalizada e monocêntrica; enquanto outra pode conformar o seu espaço urbano de modo disperso, horizontalizado e policêntrico."

Essas diferenças entre os tipos de aglomerações urbanas, em especial a dispersa, vêm preocupando muitos pesquisadores em relação aos desafios sociais e ambientais. Portanto, faz-se necessário entender a dinâmica deste fenômeno para repensar as políticas de planejamento regional (Limonad \& Costa, 2014). Apesar de serem apontados alguns padrões de comportamento constatados em estudos de caso que tratam sobre dispersão urbana realizados em outros países, em relação ao Brasil ainda é necessário realizar pesquisas para entender o fenômeno, assim como suas particularidades. "A escala sobre a qual se dá este fenômeno assume dimensões que vão além da análise da cidade ou de sua formação histórica. A escala de análise do processo de dispersão urbana 
(urban sprawl) é uma escala regional." (Ojima, 2008, p. 50).

Considerando essa perspectiva regional do desenvolvimento urbano, devemos levar em conta a dinâmica demográfica nessas novas regionalidades, pois uma análise exclusivamente baseada nos aspectos formais e construtivos da mancha urbana de uma região não permite identificar a integração de núcleos urbanos distintos. Isso significa dizer que em regiões de urbanização dispersa, mesmo em áreas urbanizadas distantes, mas que possuem um fluxo de movimentos demográficos representativos estão integrados a um mesmo processo urbano.

Da mesma maneira, uma abordagem economicista incluiria um conjunto amplo de municípios dentro do mesmo contexto metropolitano sem que necessariamente haja entre esse município e os demais uma relação de trocas populacionais significativas (Ojima et al., 2010). Assim, uma leitura demográfica do processo de expansão urbana evitaria que os fluxos econômicos que nem sempre correspondem à integração de atividades cotidianas dos indivíduos sejam incluídos na dimensão analítica.

É nesse sentido que a urbanização extravasa os limites do tecido urbano, os espaços de vida da população se expandem privilegiando a fragmentação do tempo de vivenciar tais espaços e diminuindo o potencial dos mecanismos de proteção existencial (Marandola, 2010). Elementos como a flexibilização da atividade industrial nas novas formas urbanas e de segregação socioespacial contribuem para engendrar um processo de insegurança social baseada na flexibilização dos riscos calculados pelos sujeitos, baseados nessa nova organização social que chamamos de modernidade (Giddens, 1991).

Dentro desse contexto, o planejamento urbano e regional deve buscar um novo paradigma, pois o dualismo industrialização/migração, no contexto da modernidade, passa a ser fundamentado por um tripé, onde os deslocamentos pendulares entram como o novo elemento. Se desconsiderarmos os fluxos de deslocamentos pendulares como dinâmica de organização do espaço urbano, não será possível entender completamente quais são os atores envolvidos no processo de negociação do uso do espaço.

A crise de paradigma reside na necessidade de entender as características dessas pessoas, as suas demandas, suas origens e destinos diários para dar conta dos desafios compartilhados e que, muitas vezes, passam despercebidos pelas políticas públicas que ainda esperam a confirmação de fluxos migratórios segundo experiências anteriores. Portanto, trata-se de entender como as novas interdependências entre individualização e globalização (Beck, 2010) resultam na concretude dos espaços de vida conectados, mas ao mesmo tempo fragmentados.

As pessoas estão cada vez mais demandando espaços onde possam exercer sua individualidade, ao mesmo tempo, o homem, como um ser social, necessita de espaços coletivos para se sentir parte de uma sociedade. Esses espaços vazios, as distâncias entre vizinhos, prédios, aglomerações urbanas, poderíamos interpretar como demarcações desses sujeitos que prezam por sua individualidade.

Formas urbanas mais compactas, com densidades urbanas mais elevadas e usos do solo mistos, são apontadas como economizadoras de energia, devido à elevação da eficiência das redes básicas e do sistema de transporte público, com um uso mais eficiente e estratégico do espaço urbano (Leite \& Awad, 2012), enquanto que o padrão de urbanização dispersa (urban sprawl), caracterizado por baixas densidades e usos do solo segregados, implica maior necessidade de deslocamentos por veículos motorizados, levando a um aumento das emissões de GEE (Braga, 2012, p. 5).

Mas essa relação com transportes, domicílios e população é uma espiral perversa na qual se justifica a ausência de investimentos em transporte coletivo pela sua própria decadência. Assim, a dispersão urbana nos termos aqui empregados - sendo mais do que a expressão física da cidade, mas um modo de vida fragmentado e fluido - retroalimenta a retirada completa do poder público de seu dever de oferecer mobilidade urbana à população. Nesse aspecto, o imperativo da urgência orienta para políticas urbanas que privilegiem o sistema de transporte individual.

Efeitos não planejados de um conjunto de medidas governamentais favoreceram que, entre 2000 e 2010, no Brasil, a variação da população fosse de $13 \%$, a de domicílios $28 \%$ e a frota de automóveis $86 \%$. Isso sem considerar as motocicletas que apresentaram aumento de $314 \%$ no mesmo período. Os dados indicam que a posse de automóveis está associada à idade do responsável pelo domicílio, pois as maiores taxas de motorização estão nos domicílios onde a média de idade dos moradores é maior e o número 
de pessoas por domicílio é menor (Fioravante, 2009). Neste sentido, à medida que avança a transição demográfica e a população urbana se torna mais envelhecida, tende a crescimento tanto o número de domicílios como a frota de veículos (Martine et al., 2012).

Mas há o componente local, da própria etapa da dinâmica demográfica e também do modelo de urbanização que essa região se encontra. No caso nordestino, o crescimento na frota de automóveis e de motocicletas foi mais expressivo que no restante do país, já que apresentaram uma variação de $110 \%$ e $441 \%$, respectivamente. Assim, as aglomerações urbanas nordestinas que se mostravam mais compactas (Ojima, 2007) parecem hoje caminhar para um padrão mais disperso, valendo-se de modelos de urbanização similares aos já identificados e estudados em outros contextos regionais e com uma urbanização cada vez mais dependente do transporte individual.

\section{Mobilidade populacional e o eixo sul de expansão metropolitana}

O processo de metropolização da RMN teve início nos anos 1970, entretanto, nesse período a região foi reconhecida como uma "Aglomeração Não Metropolitana", denominação feita pelo governo estadual da época (Clementino \& Souza, 2009). Nos anos seguintes foram tomadas algumas iniciativas a fim de elaborar planos de estruturação espacial e urbana que permitissem acompanhar o crescimento e desenvolvimento da região, mas - como em grande parte dos planos metropolitanos - com pequena efetividade regional (Pessoa, 2012).

Foi apenas em 1997 que foi instituída oficialmente a Região Metropolitana de Natal através da Lei Complementar n. 152 (Rio Grande do Norte, 1997). Fazendo parte os municípios de Natal, Parnamirim, São Gonçalo do Amarante, Macaíba, Ceará-Mirim e Extremoz. Em 2002, pela Lei Complementar n. 221 (Rio Grande do Norte, 2002), incluíram-se os municípios de São José do Mipibu e Nísia Floresta. Monte Alegre e Vera Cruz foram incluídas através da Lei Complementar n. 391 (Rio Grande do Norte, 2009).

Desde a instalação da base aérea americana no período da Segunda Guerra Mundial em Parnamirim, o centro urbano principal, o município de Natal, vem direcionando o desenvolvimento de infraestrutura e mudanças no modo de vida da população em direção ao eixo sul da RMN (Araújo, 2013). Considerando que essa divisão urbana é formada no âmbito políticoadministrativo, o não tratamento das questões de integração regional por parte dos agentes políticos contribuiu para acentuar as desigualdades já existentes nos municípios que compõem a RMN. Assim, Natal se tornou um forte concentrador das relações econômicas e dos serviços públicos necessários à população da RMN, reiterando as relações entre centro e periferia (Clementino, 2003). Dentro desse contexto, nosso recorte se dedica a explorar o eixo sul da RMN por concentrarem os maiores contingentes de trocas populacionais na RMN.

O município de Parnamirim, conurbado à mancha urbana natalense, teve um crescimento de $5 \%$ ao ano na década de 2000 , passando de 124,6 mil para 202,4 mil habitantes nesse período de 10 anos. Juntamente com os demais municípios do eixo sul, configura-se como um importante polo de desenvolvimento e expansão urbana que poderia ser considerado como um destino natural do crescimento urbano do município de Natal, não fosse o fato de que apenas 45,6\% dos imigrantes de Parnamirim tenham tido como residência anterior o município de Natal.

É importante destacar que mais da metade do crescimento migratório do município de Parnamirim na década de 2000 não pode ser atribuída às saídas de pessoas provenientes do município de Natal. Fato que confirma a tendência observada em outras regiões metropolitanas brasileiras, onde o crescimento dos municípios do entorno não é mais predominantemente reflexo do transbordamento dos fluxos migratórios da sede metropolitana.

No que se refere ao processo de dispersão urbana, as aglomerações urbanas nordestinas foram classificadas como compactas no estudo comparativo proposto por Ojima (2007). A partir da construção de um indicador de dispersão urbana que considerava quatro dimensões: 1) densidade populacional urbana, 2) fragmentação espacial, 3) orientação da mancha urbana, e 4) centralidade dos fluxos de deslocamentos pendulares, o estudo comparou 37 aglomerações urbanas brasileiras e identificou características mais compactas no contexto urbano nordestino. 
Nesse sentido, emerge um novo quadro para a afirmação de que a metrópole nordestina é mais compacta que aquelas das regiões Sul e Sudeste do país, como identificado por Ojima (2007). Mas o crescimento populacional mais expressivo de um município em particular, como é o caso de Parnamirim, não é suficiente para afirmar que há um processo de dispersão urbana em curso nessa aglomeração urbana. Como vimos, um indicador substantivo é o fato de que a maior parte do volume de imigrantes de Parnamirim, pelo menos por enquanto, não é oriundo da sede metropolitana.

Pode-se dizer, ainda, que Parnamirim teria características de uma cidade-dormitório, pois 18,3\% da sua população trabalham em outro município, sendo que mais que oito em cada dez dessas pessoas $(85,9 \%)$ realizam movimentos diários para trabalhar no município de Natal. Desse modo, o município de Parnamirim sozinho responde por $67 \%$ dos deslocamentos pendulares do eixo sul da RMN, seguido do município de Natal que, embora seja a sede metropolitana, apresenta um significativo volume de deslocamentos para trabalho em municípios do eixo sul, sendo a mesma Parnamirim o principal destino dessas pessoas, pois cerca de sete em cada dez deslocamentos pendulares de residentes em Natal têm como destino Parnamirim.

A importância da expansão urbana do eixo sul no contexto da região metropolitana natalense se expressa por essa dinâmica, pois cerca de $60 \%$ de todos os deslocamentos pendulares da região metropolitana como um todo estão representados na Tabela 1. Esse transbordamento dos espaços urbanos no modelo atual de expansão urbana é suscetível a vulnerabilidades sociais decorrentes da constituição de zonas de assistência ou de desfiliação (Hogan \& Marandola, 2005). Portanto, a necessidade de orientação no âmbito das políticas públicas a fim de ordenar a sua estrutura urbana e a demanda e oferta de serviços se torna mais complexa. A ação social passa a ser cada vez mais influenciada por contextos de articulação distanciados e ao mesmo tempo desconectados do espaço local, transferindo para o indivíduo a decisão de confiar ou não nos sistemas de segurança para o proteger dos riscos sociais caracterizados por essas novas formas de mobilidade (Beck, 2010).

\section{Os desafios da dispersão e o contexto potiguar}

A velocidade com que essas transformações ocorrem parece ser mais acelerada que na região Nordeste, o que deverá trazer consequências mais graves ao processo de planejamento urbano e regional. Muitos dos setores censitários mais ocupados estão entre os limites municipais de Natal e Parnamirim. Isso contribui para que o volume de deslocamentos pendulares seja mais expressivo, pois é perceptível que apesar dessa intensa integração de fluxos demográficos entre os dois municípios, na verdade trata-se de um mesmo espaço de vida compartilhado de maneira fluída e rarefeita (Marandola, 2006; Marandola \& Mello, 2005). Ou seja, um dualismo entre os dois municípios, onde uma parte de Parnamirim está completamente

Tabela 1 - Matriz de deslocamentos pendulares dos municípios de maior integração regional, Região Metropolitana de Natal - 2010

\begin{tabular}{|c|c|c|c|c|c|c|c|}
\hline \multirow[b]{2}{*}{ Municipio de Trabalho } & \multicolumn{6}{|c|}{ Municipio de Residência } & \multirow[b]{2}{*}{ TOTAL } \\
\hline & Natal & Parnamirim & Extremoz & Macaiba & $\begin{array}{l}\text { São Gonçalo } \\
\text { do Amarante }\end{array}$ & $\begin{array}{c}\text { Demais } \\
\text { municípios }\end{array}$ & \\
\hline Natal & $\star \star \star ~$ & 31.890 & 2.673 & 4.411 & 13.571 & 7.390 & 59.935 \\
\hline Parnamirim & 4.092 & 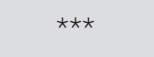 & 77 & 1.015 & 465 & 1.274 & 6.923 \\
\hline Extremoz & 4.618 & 269 & $\star \star \star ~$ & 379 & 1.386 & 556 & 7.208 \\
\hline Macaíba & 1.524 & 1.203 & 21 & $\star \star \star ~$ & 390 & 148 & 3.286 \\
\hline São Gonçalo do Amarante & 1.513 & 330 & 414 & 329 & 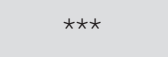 & 136 & 2.722 \\
\hline Demais municípios & 1.123 & 588 & 86 & 80 & 122 & 1.177 & 3.176 \\
\hline TOTAL & 12.870 & 34.280 & 3.271 & 6.214 & 15.934 & 10.681 & 83.250 \\
\hline
\end{tabular}

Fonte: Autor, com base em dados do Censo Demográfico de 2010 (IBGE, 2010). 
voltada para Natal, valendo-se de sua luminosidade polarizadora.

Mas o que vemos no contexto metropolitano de Natal é uma ampliação desses contextos de uso de espaços de vida. Loteamentos fechados de médio e alto padrão estão se disseminando ao longo dos setores censitários da orla de Parnamirim e, timidamente, expandindo seu alcance para algumas localidades isoladas do município de Nísia Floresta. Assim, os desafios para a gestão integrada de uma região metropolitana em expansão recente se tornam mais complexos se não forem identificados os novos fluxos e espaços de vida criados no contexto regional.

A demanda por transporte e deslocamento é apenas uma das questões que se tornam mais evidentes dentro deste cenário. Mas a lógica de exploração imobiliária também é incentivada por uma competição intermunicipal dentro dessa estrutura de dispersão urbana. Os loteamentos de médio e alto padrão tendem a receber incentivos fiscais por parte dos municípios do entorno que se valem desta dinâmica de acessibilidade aos serviços da rede urbana metropolitana (Ojima \& Hogan, 2009).

A Figura 2 ilustra número médio de moradores por domicílio dos setores censitários urbanos dos municípios de Extremoz (ao norte), São Gonçalo do Amarante (a oeste), Parnamirim (ao sul) e Natal. São os municípios que apresentam maior dinâmica populacional com o município-sede e é possível perceber, a despeito do elevado ritmo de crescimento populacional dos municípios do entorno metropolitano, sobretudo de Parnamirim, entre 2000 e 2010, que a densidade domiciliar é cada vez menor. Isso reflete o processo de transição demográfica ora discutido neste artigo e que aponta para famílias e domicílios com um número menor de moradores.

Portanto, fica evidente que os fatores demográficos são fundamentais para entender o processo de ocupação urbano metropolitano. Mas principalmente que não se trata apenas de analisar o ritmo de crescimento absoluto, pois a composição
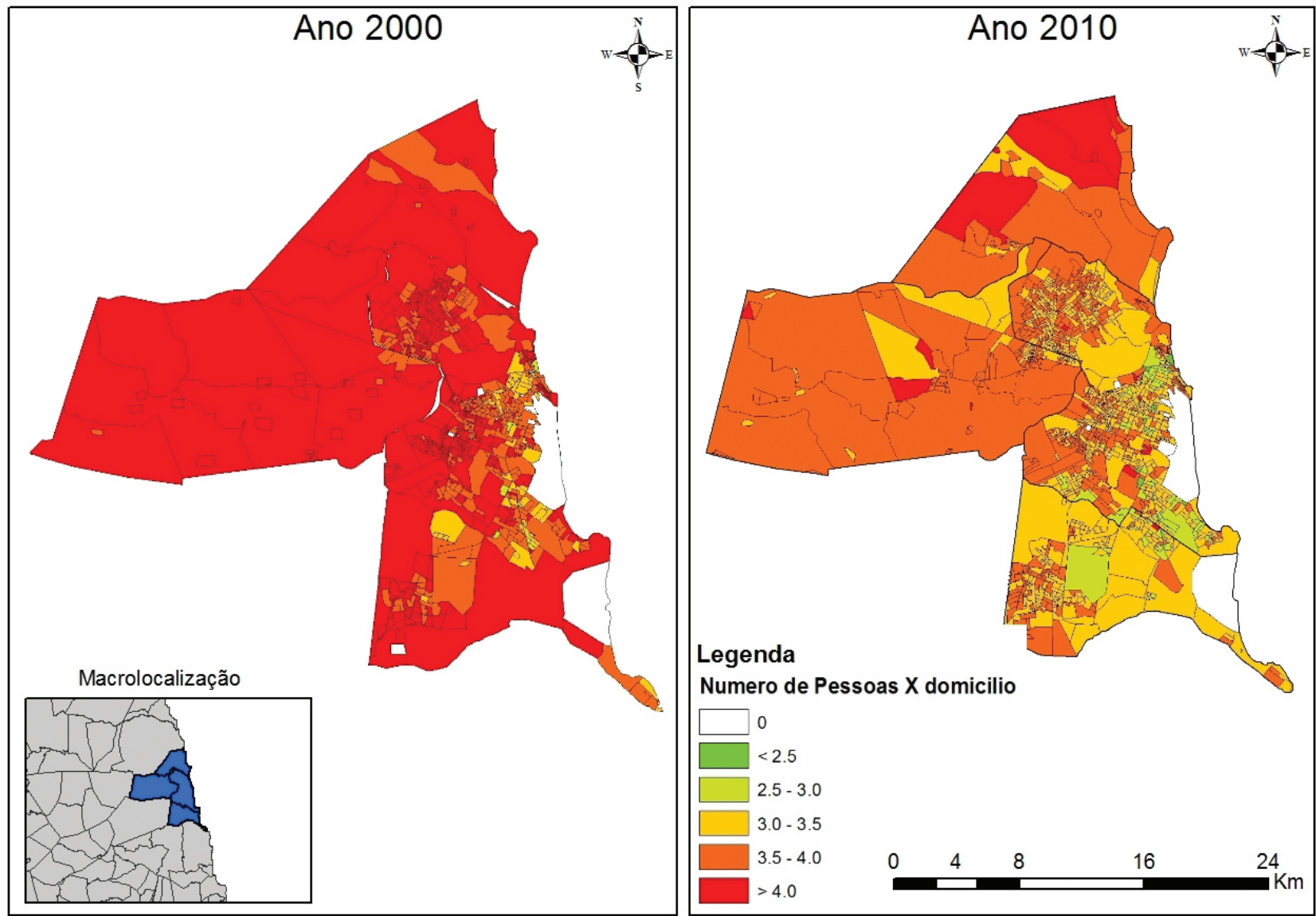

Figura 2 - Número médio de moradores por domićlio dos setores censitários urbanos, municipios limítrofes a Natal - 2000 e 2010 Fonte: Autor, com base em dados dos censos demográficos de 2000 e de 2010 (IBGE, 2000, 2010). 
da população e seu estágio no processo de transição demográfica influenciam fortemente na forma de viver a cidade. Ou seja, depende fortemente dos fatores demográficos a ampliação do espaço de vida urbano e, portanto, do processo de dispersão urbana.

Esse fato se confirma analisando a Figura 3, pois apesar da diminuição do número médio de moradores por domicílio em toda a região e com mais evidência no sentido do eixo sul, pode-se perceber que há uma variação positiva na população residente nos setores censitários urbanos, sobretudo nas regiões mais afastadas do centro urbano consolidado de Natal. Assim, sendo a região com maior dinamismo populacional, o eixo sul se caracteriza fortemente como a área de expansão da dispersão urbana da RMN. Ou seja, o crescimento populacional associado

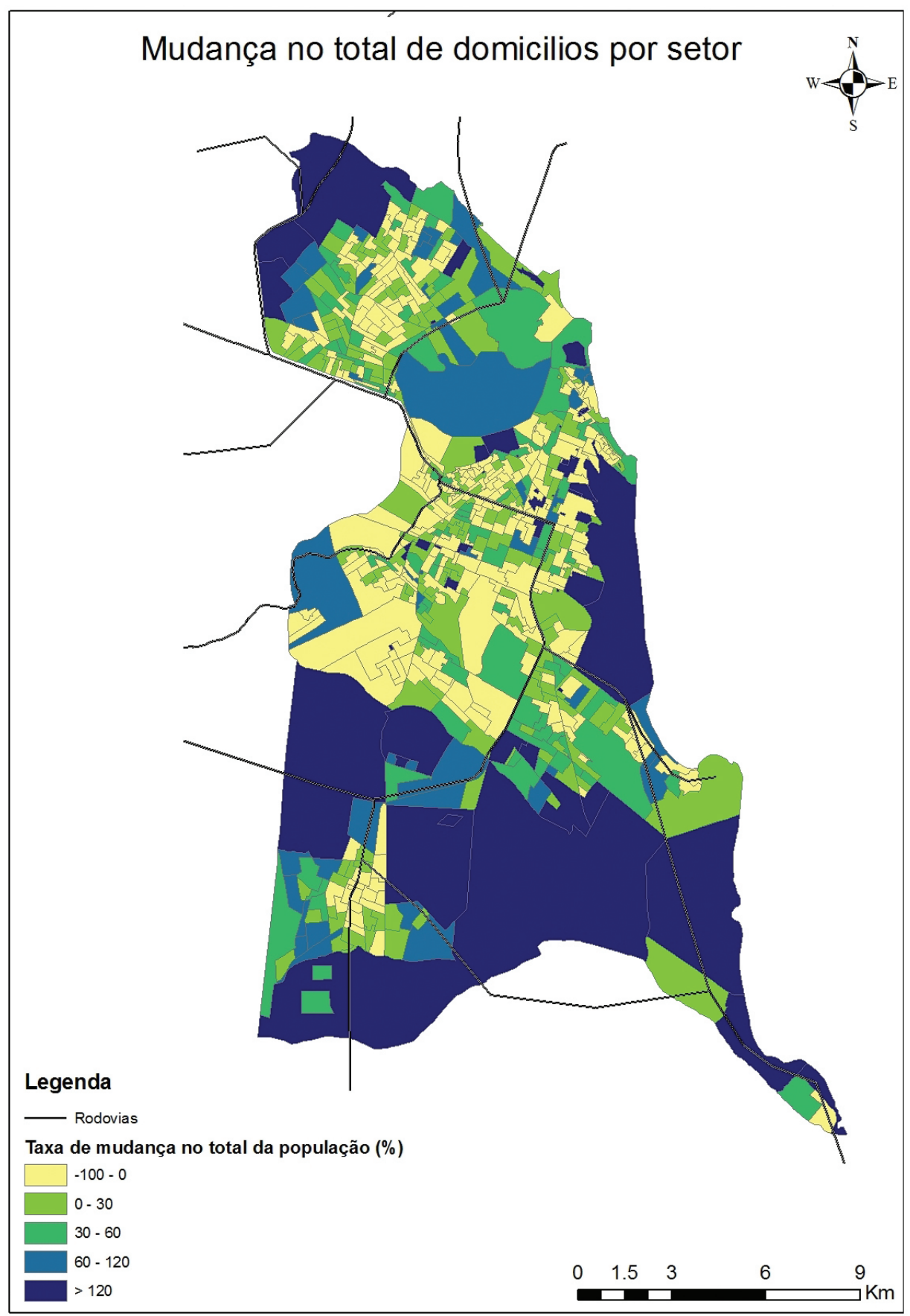

Figura 3 - Variaç̃ão da população (em \%) nos setores censitários, Natal e Parnamirim - 2000 e 2010 Fonte: Autor, com base em dados dos censos demográficos de 2000 e de 2010 (IBGE, 2000, 2010). 
às menores densidades de moradores por domicílio, ampliando a ocupação do espaço de maneira distinta do processo de ocupação concentrador e denso de contextos de desenvolvimento anteriores.

\section{Considerações finais}

A expansão urbana acelerada nesse novo contexto contemporâneo constitui-se, portanto, em uma nova forma de viver a cidade. Uma cidade líquida onde há um descompasso entre o espaço de vida urbano e o espaço de vida social. A política urbana deveria, portanto, seguir alguns princípios básicos, buscando recuperar a função social da cidade de modo a integrar essas dimensões e favorecer uma visão integrada e sistêmica da cidade para o indivíduo.

Mas a participação da população nos mecanismos de gestão local, ao mesmo tempo em que se torna um contexto privilegiado de transformação, tornase uma demanda pouco exercida pela comunidade, pois a vida cotidiana na cidade dispersa passa a ser fragmentada devido à fluidez dos nexos da mobilidade espacial. Ou seja, a fragmentação espacial ao mesmo tempo em que expande os espaços de vida individual (Marandola, 2006; Marandola \& Mello, 2005), também cria um efeito de desfiliação social no local de residência e de trabalho.

Essa condição propicia um avanço da sociedade moderna para um processo de liquefação, onde "os fluidos se movem facilmente” (Bauman, 2001, p. 8). Na maioria dos casos, a ausência de políticas sociais e a separação dos grupos sociais no espaço (processos que caracterizam a segregação) retroalimentam as desigualdades sociais características do modelo de acumulação produtivo. Mas as pessoas se moldam, se ajustam às condições existentes e exercem a sua mobilidade no espaço urbano a fim de garantir sua reprodução social e até mesmo a mobilidade social. Assim, o estilo de vida que é engendrado pelo urbano torna-se um aspecto que serve para agravar ou não a vulnerabilidade social nos novos contextos da urbanização.

Baseado nessa análise, podemos dizer que os elementos para a dispersão urbana já se encontram evidentes no contexto das regiões metropolitanas nordestinas. Essas regiões, tradicionalmente mais compactas, passam por mudanças importantes nos últimos anos que a colocam nessa nova trajetória.
Assim, detalhar os fatores demográficos contribui para entender a urbanização recente, uma vez que permite analisar o processo para além da materialidade intrínseca da cidade formal, cidade edificada. Afinal, é a partir da mudança na forma das pessoas viverem e se deslocarem pela cidade que o urbano formal vai se redesenhar nos próximos anos.

Se o planejamento metropolitano não levar em conta que novas dinâmicas de espaços de vida ampliados associados à urbanização dispersa que estão surgindo no contexto regional, o risco de que novas vulnerabilidades sociais passem despercebidas ao poder público aumenta consideravelmente. Nesse caso, o desafio de gestão se torna uma questão praticamente insolúvel, pois a ausência de uma instância legítima de poder supramunicipal que regule a lógica da ampliação dos espaços de vida faz com que a metrópole apresente efetivamente uma dinâmica populacional regional, favorecendo uma maior dispersão.

\section{Referências}

Abramo, P. (2007). A cidade com-fusa: a mão inoxidável do mercado e a produção da estrutura urbana nas grandes metrópoles latino-americanas. Revista Brasileira de Estudos Urbanos e Regionais, 9(2), 25-54p.

Andrade, M. C., \& Andrade, S. M. C. (2003). A federação brasileira: uma análise geopolítica e geo-social (2a ed.). São Paulo: Contexto.

Araújo, F. F. (2013). Produção do espaço urbano e processos espaciais em Natal: o conjunto Ponta Negra em foco. Cadernos Metrópole, 15(30), 627-644. http://dx.doi. org/10.1590/2236-9996.2013-3012.

Bauman, Z. (2001). Modernidade líquida. Rio de Janeiro: Jorge Zahar.

Beck, U. (2010). Sociedade de risco. São Paulo: Ed. 34.

Braga, R. (2012). Mudanças climáticas e planejamento urbano: uma análise do Estatuto da Cidade. In Anais do VI Encontro Nacional da Anppas (p. 1-15). Bélem: ANPPAS. Recuperado em 20 de fevereiro de 2014, de http://www. anppas.org.br/encontro6/anais/ARQUIVOS/GT11-443138-20120629113805.pdf 
Clementino, M. L. M. (2003). A região metropolitana e o parlamento comum: a carta de vereadores da grande Natal. Cadernos Metrópole, 10, 27-54.

Clementino, M. L. M., \& Souza, M. A. A. (2009). Como andam Natal e Recife. Rio de Janeiro: Letra Capital.

Fioravante, E. F. (2009). Projeção de domicílios por modelo multi-estado e aplicação para previsão da frota de automóveis em Belo Horizonte (Tese de Doutorado). Programa de Pós Graduação em Demografia, Universidade Federal de Minas Gerais, Belo Horizonte.

Giddens, A. (1991). As consequências da modernidade. São Paulo: Ed. UNESP.

Gomes, P. C. C. (2012). A condição urbana: ensaios de geopolítica da cidade (4a ed.). Rio de Janeiro: Ed. Bertrand Brasil.

Gottdiener, M. (2010). A produção social do espaço urbano. São Paulo: EDUSP.

Harvey, D. (2004). Espaços de esperança. São Paulo: Edições Loyola.

Hogan, D. J., \& ; Marandola, E., Jr. (2005). Towards an interdisciplinary conceptualisation of vulnerability. Population, Space and Place, 11(6), 455-471. http://dx.doi. org/10.1002/psp.401.

Hogan, D. J., \& Ojima, R. (2008). Urban sprawl: a challenge for sustainability. In G. Martine, G. McGranahan, M. Montgomery, \& R. Fernández- Castilla (Orgs.), The new global frontier: urbanization, poverty and environment in the 21st century (1a ed., p. 205-219). London: IIED/UNFPA and Earthscan Publications.

Instituto Brasileiro de Geografia e Estatística - IBGE (1950). Censo Demográfico 1950. Rio de Janeiro: IBGE.

Instituto Brasileiro de Geografia e Estatística - IBGE (1960). Censo Demográfico 1960. Rio de Janeiro: IBGE.

Instituto Brasileiro de Geografia e Estatística - IBGE (1970). Censo Demográfico 1970. Rio de Janeiro: IBGE.

Instituto Brasileiro de Geografia e Estatística - IBGE (1980). Censo Demográfico 1980. Rio de Janeiro: IBGE.

Instituto Brasileiro de Geografia e Estatística - IBGE (1991). Censo Demográfico 1991. Rio de Janeiro: IBGE.

Instituto Brasileiro de Geografia e Estatística - IBGE (2000). Censo Demográfico 2000. Rio de Janeiro: IBGE.
Instituto Brasileiro de Geografia e Estatística - IBGE (2010). Censo Demográfico 2010. Rio de Janeiro: IBGE.

Leite, C., \& Awad, J. C. M. (2012). Cidades sustentáveis, cidades inteligentes: desenvolvimento sustentável em um planeta urbano. Porto Alegre: BOOKMAN.

Limonad, E. (2007). No todo acaba en Los Angeles ¿un nuevo paradigma: entre la urbanización concentrada y dispersa? Biblio $3 W, 12(734)$. Recuperado em 20 de fevereiro de 2014, de http://www.ub.es/geocrit/b3w734.htm

Limonad, E., \& Costa, H. (2014). Edgeless and eccentric cities or new peripheries? Bulletin of Geography. Socioeconomic Series, 24(24), 117-134. http://dx.doi. org/10.2478/bog-2014-0018.

Marandola, E., Jr. (2010). Cidades médias em contexto metropolitano: hierarquias e mobilidades nas formas urbanas. In R. Baeninger (Org.), População e cidades: subsídios para o planejamento e para as políticas sociais (p. 187-207). Campinas: NEPO/Unicamp; Brasília: UNFPA.

Marandola, E., Jr. (2006). Mobilidade e vulnerabilidade nos espaços de vida de Campinas. In Anais do XV Encontro Nacional de Estudos Populacionais (p. 1-20). Campinas: ABEP. Recuperado em 20 de fevereiro de 2014, de http:// www.abep.nepo.unicamp.br/encontro2006/docspdf/ ABEP2006_576.pdf

Marandola, E., Jr., \& Mello, L. F. (2005). "Lugar" e "espaço de vida": novos enfoques para o planejamento e a participação? In Anais do X Encontro Latino-Americano De Geógrafos (1 CD ROM, p. 8502-8522), São Paulo: DG/ FFLCH/USP.

Martine, G., \& Ojima, R. (2012). The challenges of adaptation in the context of an early but unassisted urban transition. In G. Martine, \& D. Schensul (Eds.), The demography of adaptation to climate change (p. 138-157). New York: UNFPA.

Martine, G., Ojima, R., \& Fioravante, E. F. (2012). Transporte indivudual, dinâmica demográfica e meio ambiente. In G. Martine, R. Ojima, A. F. Barbieri, \& R. L. Carmo. População e sustentabilidade na era das mudanças ambientais globais (p. 175-185). Campinas: ABEP. 
Ojima, R. (2007). Dimensões da urbanização dispersa e proposta metodológica para estudos comparativos: uma abordagem socioespacial em aglomerações urbanas brasileiras. Revista Brasileira de Estudos de Populacao, 24(2), 277-300. http://dx.doi.org/10.1590/ S0102-30982007000200007.

Ojima, R. (2008). Novos contornos do crescimento urbano brasileiro? 0 conceito de urban sprawl e os desafios para o planejamento regional e ambiental. GEOgraphia, 10(19), 46-59.

Ojima, R., \& Hogan, D. J. (2009). The demographic composition of urban sprawl: local and regional challenges concerning global environmental change in Brazilian metropolitan areas. In Proceedings of the XXVI IUSSP International Population Conference (p. 1-16). Marrakech: IUSSP. Recuperado em 20 de fevereiro de 2014, de http:// iussp2009.princeton.edu/papers/90294

Ojima, R., Marandola, E., Jr., Pereira, R. H. M., \& Silva, R. B. (2010). 0 estigma de morar longe da cidade: repensando o consenso sobre as cidades-dormitório. Cadernos Metrópole, 12(24), 395-415.

Ojima, R., \& Marandola, E., Jr. (2012). O desenvolvimento sustentável como desafio para as cidades brasileiras. Cadernos ADENAUER, 1, 23-35.

Pessoa, Z. (2012). A metrópole periférica: identidade e vulnerabilidade socioambiental na Região Metropolitana de Natal-RN/Brasil (Tese de doutorado). Programa de Pós-graduação em Ambiente e Sociedade, Universidade Estadual de Campinas, Campinas.

Polidoro, M., Lollo, J. A., \& Barros, M. V. F. (2012). Sprawl e o modal de transporte motorizado: impactos na cidade de Londrina, PR. urbe. Revista Brasileira de Gestão Urbana, 4(1), 33-46. http://dx.doi.org/10.7213/urbe.6028.
Reis, N. G. (2006). Notas sobre urbanização dispersa e novas formas de tecido urbano. São Paulo: Via das Artes.

Rio Grande do Norte (1997, 6 de fevereiro). Lei Complementar $n$. 152, de 16 de janeiro de 1997. Institui a Região Metropolitana de Natal e dá outras providências. Rio Grande do Norte: Diário Oficial do Estado, p. 8-9.

Rio Grande do Norte (2002, 11 de janeiro). Lei Complementar n. 221, de 10 de janeiro 2002. Altera dispositivos da Lei Complementar n. 152, de 16 de janeiro de 1997, que dispõe sobre a Região Metropolitana de Natal, e dá outras providências. Rio Grande do Norte: Diário Oficial do Estado, p. 1.

Rio Grande do Norte (2009, 23 de julho). Lei Complementar n. 391, de 22 de julho de 2009. Altera dispositivo da Lei Complementar n. 315, de 30 de novembro de 2005, que dispõe sobre a Região Metropolitana de Natal, e dá outras providências. Rio Grande do Norte: Diário Oficial do Estado, p. 41.

Santoro, P. F., \& Bonduki, N. G. (2009). O desafio do parcelamento do solo a partir do periurbano: a composição do preço da terra na mudança de uso do solo rural para urbano. In Anais do XIII ENANPUR - Encontro Nacional da ANPUR. Florianópolis: ANPUR.

Souza, M. L. (2006). A prisão e a ágora: reflexões em torno da democratização do planejamento e da gestão das cidades. Rio de Janeiro: Bertrand Brasil.

United Nations Population Fund - UNFPA (2007). Situação da População Mundial 2007: Desencadeando o Potencial do Crescimento Urbano. Nova York: UNFPA.

Urry, J. (2007). Mobilities. London: Polity.

Recebido: Mar. 26, 2014

Aprovado: Jul. 3, 2014 